\title{
PENGARUH TINGKAT PENGANGGURAN DAN PENGELUARAN PEMERINTAH TERHADAP PERTUMBUHAN EKONOMI DI KABUPATEN ACEH UTARA TAHUN 2007-2016
}

Devi Andriyani ${ }^{* a}$, Nurmauliza ${ }^{* b}$
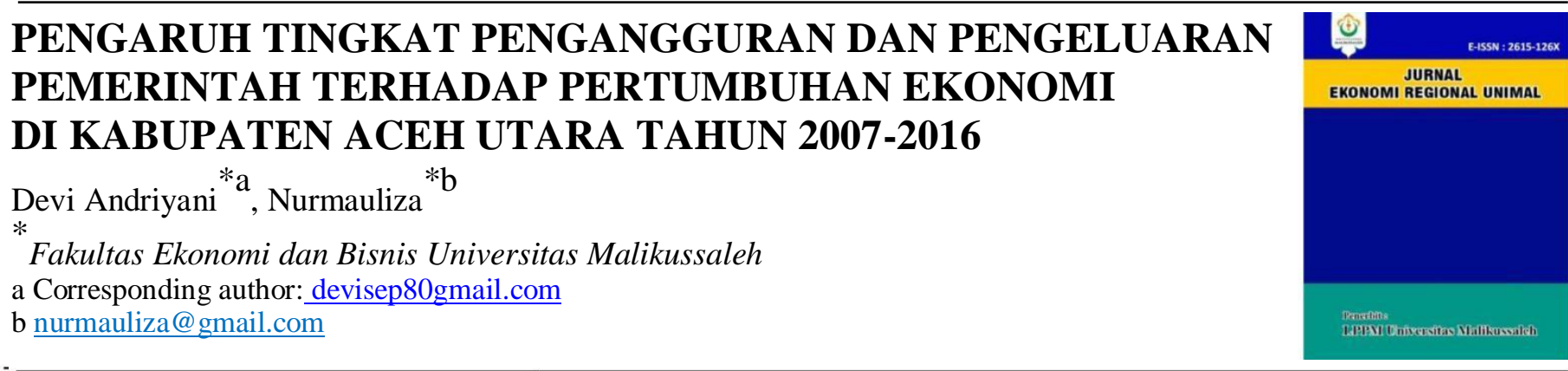

ARTICLE INFORMATION

A B S T R A C T

Keywords:

Unemployment Rate, Government Expenditures and Economic Growth.
This study aims to determine the Effect of Unemployment Rate and Government Expenditures on Economic Growth in North Aceh District, Indonesia in the 2007-2016. The data used in this study are secondary data sourced from the North Aceh Regency Central Bureau of Statistics (BPS) 2007-2016. The data analysis method used in this study is the Multiple Linear Regression model. The results showed that the variable partially unemployment rate had a negative and significant effect on economic growth and government expenditure variables had a negative and significant effect on economic growth in North Aceh District. While simultaneously (together) the unemployment rate and government expenditure variables had a positive and significant effect on economic growth in North Aceh District in the year 2007-2016.

\section{PENDAHULUAN}

Sebagai negara berkembang pemerintah memiliki peran penting dalam mempercepat pembangunan ekonomi. Berbagai kebijakan dilakukan dalam pencapaian tujuan pembangunan ekonomi. Kebijakan fiskal adalah kebijakan ekonomi yang dilakukan oleh pemerintah terhadap penerimaan dan pengeluaran untuk mencapai tujuan seperti pertumbuhan ekonomi dan stabilitas perekonomian secara umum. Pengeluaran Pemerintah (goverment expenditure) merupakan bagian dari kebijakan fiskal (Sukirno, 2002),yaitu suatu tindakan pemerintah untuk mengatur jalannya perekonomian. Pertumbuhan ekonomi merupakan suatu tolak ukur untuk keberhasilan pembangunan di suatu Negara khususnya dibidang ekonomi.

Pemerintah tidak cukup hanya meraih tujuan akhir dari setiap kebijakan pengeluarannya, akan tetapi harus memperhitungkan sasaran antara yang akan menikmati atau terkena kebijakan tersebut, misalnya terhadap pengangguran.

Menurut (Sukirno, 2006) pengangguran adalah masalah yang sangat buruk efeknya kepada perekonomian dan masyarakat. Pengangguran yang tinggi mempunyai dampak buruk baik terhadap perekonomian, individu dan masyarakat, apabila tingginya jumlah pengangguran akan menyebabkan masyarakat tidak dapat memaksimumkan kesejahteraan yang mungkin dicapai, produktivitas dan pendapatan masyarakat akan berkurang sehingga timbul kemiskinan, kejahatan, dan masalah sosial lainnya.

Pada hakikatnya, pembangunan ekonomi ditinjau bagi pengembangan kelompok usaha dan kebijakan pemerintah yang tujuannya adalah untuk meningkatkan taraf hidup masyarakat, memperluas lapangan kerja, memeratakan pembagian pendapatan masyarakat, mengurangi tingkat pengangguran yaitu dengan menciptakana lapangan kerja. Namun walaupun demikian Aceh Utara masih tergolong dengan tingkat pengangguran yang tinggi walapun tingkat pengeluaran pemerintah Kabupaten Aceh Utara mengalami peningkatan setiap tahunnya akan tetapi pemerintahan Aceh Utara belum mampu sepenuhnya menyediakan lapangan kerja supaya tingkat penganggurandi Kabupaten Aceh Utara 
menurun. Berikut adalah data pengangguran, pengeluaran pemerintah dan pertumbuhan ekonomi Kabupaten Aceh Utara .

\section{Tabel 1}

Data Pertumbuhan Ekonomi,Tingkat Pengangguran Dan Pengeluaran Pemerintah Di Kabupaten Aceh Utara Tahun (2007-2010)

\begin{tabular}{|l|l|l|l|}
\hline Tahun & $\begin{array}{l}\text { Pertumbuhan } \\
\text { ekonomi } \\
(\%)\end{array}$ & $\begin{array}{l}\text { Tingkat } \\
\text { Pengangguran } \\
(\%)\end{array}$ & $\begin{array}{l}\text { Pengeluaran } \\
\text { Pemerintah } \\
(\mathrm{Rp})\end{array}$ \\
\hline 2007 & 9,88 & 13.35 & $1.412 .217 .578 .000,00$ \\
\hline 2008 & $-11,96$ & 14.02 & $1.611 .234 .301 .975,00$ \\
\hline 2009 & 2,98 & 11.00 & $1.280 .245 .802 .920,15$ \\
\hline 2010 & 2,40 & 12.78 & $868.281 .536 .261,70$ \\
\hline
\end{tabular}

Sumber: Bps.Kabupaten Aceh Utara(2017)

Berdasarkan tabel 1 di atas menunjukkan bahwa pertumbuhan ekonomi, tingkat pengangguran dan pengeluaran pemerintah di Kabupaten Aceh Utara pada periode 2007-2010 mengalami fluktuasi.

Pada tahun 2007-2008 pengangguran meningkat dari 13.35 persen menjadi 14.02 persen dan pertumbuhan ekonomi terjadi penurunan. Kemudian pada periode tahun 2009-2010 pengangguran terjadi peningkatan dari 11.00 persen menjadi 12.78 persen dan pertumbuhan ekonomi juga terjadi peningkatan sejumlah kecil yaitu 2,40 persen. Hal ini tentu tidak sesuai dengan teori yang dikemukakan oleh para ahli. Fenomena inilah yang membuat peneliti ingin meneliti tingkat pengangguran di Kabupaten Aceh Utara.

Pada tahun 2007-2008 pengeluaran pemerintah meningkat sebesar Rp. 1.611.234.301.975,00. Akan tetapi pertumbuhan ekonomi mengalami penurunan sebesar -11.96 persen. Sedangkan pada tahun 2008-2009 pengeluaran pemerintah menurun sebesar Rp. 1.280.245.802.920,15 dan pertumbuhan ekonomi meningkat sebesar 2.98 persen. Hal ini tentu tidak sesuai dengan teori yang menjelaskan peningkatan pengeluaran pemerintah sejalan dengan peningkatan kegiatan ekonomi suatu negara, Karena jika pengeluaran pemerintah mengalami peningkatan maka pertumbuhan ekonomi juga akan meningkat

Dari penjelasan dan fenomena diatas penulis ingin mengetahui apakah pengangguran dan pengeluaran pemerintah berpengaruh terhadap pertumbuhan ekonomi di Kabupaten Aceh Utara.

\section{TINJAUAN PUSTAKA}

\subsection{Pertumbuhan Ekonomi}

Menurut (Pramesthi, 2011) pertumbuhan ekonomi adalah suatu kondisi dimana terjadinya perkembangan GNP yang mencerminkan adanya pertumbuhan output perkapita dan meningkatnya standar hidup masyarakat. Pertumbuhan ekonomi berkaitan dengan kenaikan output perkapita , Adapun yang perlu diperhatikan yaitu dari sisi output totalnya Gross Domestic Product GDP) dan sisi jumlah penduduknya. Output perkapita adalah kenaikan output total dibagi jumlah penduduk.

\subsection{Pengangguran}

Menurut (Sukirno, 2006) pengangguran adalah masalah yang sangat buruk efeknya kepada perekonomian dan masyarakat. Pengangguran yang tinggi mempunyai dampak buruk baik terhadap perekonomian, individu dan masyarakat, seperti tingginya jumlah pengangguran akan menyebabkan masyarakat tidak dapat memaksimumkan kesejahteraan yang mungkin dicapai, produktivitas dan pendapatan masyarakat akan berkurang sehingga timbul kemiskinan, kejahatan, dan masalah sosial lainnya.

\subsection{Pengeluaran pemerintah}

Menurut (Suindyah, 2011) Pengeluaran pemerintah adalah sekelompok produk yang dihasilkan untuk membuat pilihan atau keputusan yang dibuat oleh pemerintah untuk menyediakan barang-barang publik dan pelayanan kepada masyarakat.

Menurut (Mankiw, 2007) menjelaskan bahwa dengan adanya kenaikan pengeluaran pemerintah (ekspansi fiskal) maka akan menghambat investasi, yang pada gilirannya menurunkan kesempatan kerja dan pertumbuhan ekonomi.

\section{METODE PENELITIAN}

Objek dalam penelitian ini adalah tingkat pengangguran, pengeluaran pemerintah dan pertumbuhan ekonomi. Data yang diambil yaitu tahun 2007-2016. Lokasi Penelitian ini dilakukan di Kabupaten Aceh Utara. Penelitian ini 
menggunakan data sekunder yakni data yang diperoleh dari badan pusat statistik kabupaten Aceh Utara.

Variabel penelitian terdiri dari dua variabel $X$ sebagai variabel independen dan satu variabel $Y$ sebagai variabel dependen. Adapun variabelnya meliputi:

1. Pertumbuhan ekonomi (Y), adalah pertumbuhan ekonomi adalah perkembangan kegiatan dalam perekonomian yang menyebabkan barang dan jasa yang diproduksikan dalam masyarakat bertambah sehingga perekonomian meningkat. Peningkatan perekonomian suatu Negara dapat diukur dari perkembangan PDRB yaitu dihitung dari tahun yang sedang berjalan dengan tahun sebelumnya, diukur dengan persen.

2. Tingkat Pengangguran $\left(X_{1}\right)$, adalah suatu tindakan yang dilakukan jika seseorang tidak memiliki pekerjaan tetapi mereka sedang melakukan usaha secara aktif dalam empat minggu terakhir untuk mencari pekerjaan yang diukur dengan persen.

3. Pengeluaran pemerintah $\left(X_{2}\right)$, adalah kewajiban yang harus dibayar oleh pemerintah kabupaten/ kota, baik oleh pemerintah pusat melalui APBN maupun pemerintah daerah melalui APBD, untuk membiayai kegiatan pembangunan suatu daerah dalam periode tertentu yaitu dalam jangka waktu satu tahun anggaran yang diukur dengan rupiah.

Metode analisis data yang digunakan adalah metode penelitian kuantitatif. Metode penelitian kuantitatif adalah menggunakan angka dalam penyajian data dan analisisnya menggunakan uji statistika (Saebeni, 2008). Untuk melihat pengaruh tingkat pengangguran dan pengeluaran pemerintah terhadap pertumbuhan ekonomi dalam penelitian ini digunakan model regresi linier berganda. Adapunmodel regresi linier berganda tersebut dapat dieumuskan sebagai berikut :

$$
Y=\beta o+\beta_{1} X_{1}+\beta_{2} X_{2}+e
$$

Keterangan :
Y

ßo

$\beta_{1}, \beta_{2}$

variabel

$\mathrm{X}_{1}$

$\mathrm{X}_{2}$

$\mathrm{e}$
: Pertumbuhan ekonomi

: Konstanta

: Koefisien regresi masing-masing

: Tingkat Pengangguran

: Pengeluaran pemerintah

: Error term (Variabel Penganggu)
Model regresi linear berganda tersebut dirubah dalam bentuk persamaan logaritma linear (log-linear) seperti berikut :

$$
Y=\beta o+\beta_{1} X_{1}+\beta_{2} \log X_{2}+e
$$

Keterangan :

Y : Pertumbuhan ekonomi

Bo $\quad$ : Konstanta

$\beta_{1}, \beta_{2} \quad$ : Koefisien regresi masing-masing variabel

$\mathrm{X}_{1}$

$\mathrm{X}_{2} \quad$ : Pengeluaran pemerintah

e : Error term (Variabel Penganggu)

\subsection{Uji Asumsi Klasik}

\subsubsection{Uji Normalitas}

Menurut (Ghozali, 2012) Uji normalitas bertujuan untuk menguji apakah dalam model regresi, variabel pengganggu atau residual memiliki distribusi normal.

\subsubsection{Uji Multikolinieritas}

Pengujian multikolinieritas dilakukan dengan tujuan untuk variabel-variabel bebas (independen). Model regresi yang baik seharusnya tidak terjadi korelasi diantara variabel bebas.

Menurut (Ghozali, 2005) Pengujian multikolonieritas dapat dilakukan dengan melakukan nilai tolerance atau lawannya variance inflaction faktor (VIF). Kedua ukuran ini menunjukkan setiap variabel bebas manakah yang dijelaskan oleh variabel bebas lainnya.

\subsubsection{Uji autokolerasi}

Uji autokolerasi bertujuan untuk menguji apakah dalam model regresi linier berganda ada kolerasi atau kesalahan penganggu pada periode sebelumnya.

\subsection{Pengujian Hipotesis \\ 3.2.1 Pengujian Parsial (Uji t)}

Menurut (Gujarati, 2003) uji t bertujuan untuk melihat signifikan dari pengaruh variabel 
bebas secara individual terhadap variabel terikat dengan menganggap variabel bebas lainnya adalah konstan.

\subsubsection{Pengujian Simultan (Uji F)}

Menurut (Gujarati, 2003) uji F bertujuan untuk meilihat signifikan dari pengaruh variabel bebas secara bersama-sama terhadap variabel terikat dengan menganggap variabel bebas adalah konstan.

\subsection{Koefisien Determinasi $\left(\mathbf{R}^{2}\right)$}

Koefisian determinasi $\left(\mathrm{R}^{2}\right)$ adalah untuk mengukur seberapa jauh kemampuan model dalam menerangkan variasi variabel dependen. Nilai koefisien determinasi adalah antara 0 dan $1\left(0 \leq \mathrm{R}^{2}\right.$ $\leq 1)$.

\section{HASIL PENELITIAN DAN PEMBAHASAN}

Untuk mengetahui hasil penelitian ini dapat dilihat dari output regresi linier berganda yang memakai program Eviews 9 sebagai alat analisis pada tabel 2 berikut ini :

\section{Tabel 2}

Hasil Regresi dari Tingkat Pengangguran dan Pengeluaran Pemerintah yang mempengaruhi Pertumbuhan Ekonomi di Kabupaen Aceh Utara tahun 2007-2016

Dependent Variable: PE

Method: ARMAMaximumLikelihood(OPG - BHHH)

Date: 08/29/18 Time: 12:33

Sample: 2007M01 2016M12

Included observations: 120

Convergence achieved after 25 iterations

Coefficient covariance computed using outer product of gradients

\begin{tabular}{lcccc}
\hline \hline \multicolumn{1}{c}{ Variable } & Coefficient & Std. Error & t-Statistic & Prob. \\
\hline \hline \multicolumn{1}{c}{ C } & 351.3841 & 55.28552 & 6.355807 & 0.0000 \\
PENGANGGURAN & -0.887338 & 0.164301 & -5.400682 & 0.0000 \\
LOG(PENG_PEMERI & & & & \\
\multicolumn{1}{c}{ NTAH) } & -12.06171 & 1.917488 & -6.290368 & 0.0000 \\
AR(1) & 0.924341 & 0.090625 & 10.19968 & 0.0000 \\
$\quad$ SIGMASQ & 6.198020 & 0.535948 & 11.56460 & 0.0000 \\
\hline \hline & & & & -0.719750 \\
R-squared & 0.851469 & Mean dependent var & 6.486865 \\
Adjusted R-squared & 0.846303 & S.D. dependent var & 4.761498 \\
S.E. of regression & 2.543128 & Akaike info criterion & 4.877644 \\
Sum squaredresid & 743.7624 & Schwarz criterion & 4.808665 \\
Loglikelihood & -280.6899 & Hannan-Quinn criter. & 1.913155 \\
F-statistic & 164.8121 & Durbin-Watson stat & \\
Prob(F-statistic) & 0.000000 & & & \\
Sumber : Data diolah (2018) & &
\end{tabular}

Berdasarkan data dari Tabel 2 di atas dapat dibuat persamaan Linier Berganda sebagai berikut

$$
\mathrm{Y}=351.38-0.887 \mathrm{X} 1-12.062 \mathrm{X} 2
$$

Dari formulasi model di atas menunjukkan bahwa nilai variabel konstanta sebesar 351.38, yang berarti bahwa apabila tingkat pengangguran (X1) dan pengeluaran pemerintah (X2) nilainya 0 atau konstan, maka pertumbuhan ekonomi (Y) juga akan kosntan sebesar 351.3841 persen. Koefisien regresi tingkat pengangguran (X1) sebesar -0.887, yang berarti bahwa apabila tingkat pengangguran meningkat 1 persen maka pertumbuhan ekonomi (Y) akan menurun sebesar 0.887 persen. Sedangkan untuk koefisien regresi pengeluaran pemerintah (X2) adalah sebesar 12.062 , yang berarti bahwa apabila pengeluaran pemerintah meningkat sebesar 1 persen maka pertumbuhan ekonomi (Y) akan menurun sebesar 12.062 persen.

\subsection{Uji Normalitas}

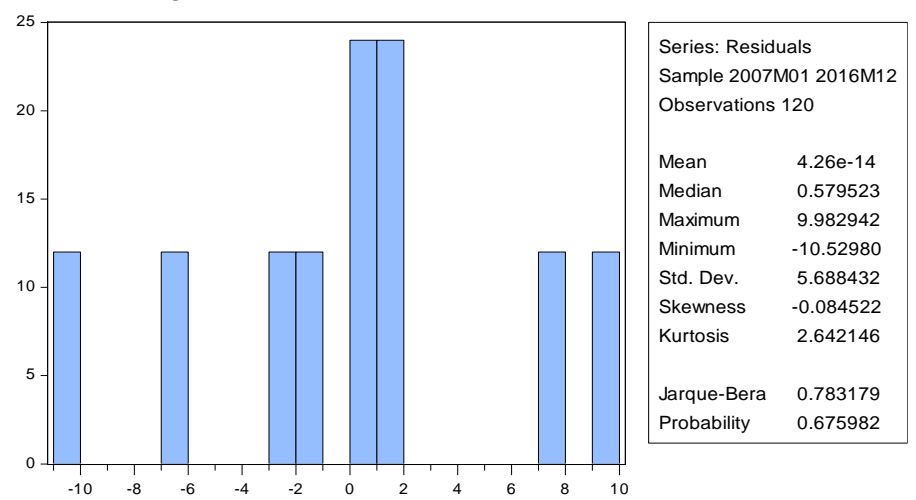

Sumber : Data diolah (2018)

\section{Gambar 1 Hasil Uji Normalitas}

Dari gambar diatas dapat disimpulkan bahwa data yang digunakan dalam penelitian ini sudah berdistribusi normal, terlihat pada nilai probabilitas sebesar $0.675982>0,05$ maka dapat disimpulkan bahwa data dalam model tersebut sudah terdistribusi normal.

\subsection{Uji Asumsi Klasik \\ 4.2.1 Uji Multikolinearitas}

Tabel 3

Hasil Uji Multikolinearitas Metode Matriks

\begin{tabular}{|c|c|c|}
\hline & Pengangguran & $\begin{array}{c}\text { Pengeluaran } \\
\text { Pemerintah }\end{array}$ \\
\hline Pengangguran & 1.000000 & $\begin{array}{c}0.625921588 \\
025337\end{array}$ \\
\hline $\begin{array}{c}\text { Pengeluaran } \\
\text { Pemerintah }\end{array}$ & 0.62592158802 & \\
& 5337 & 1.000000 \\
\hline
\end{tabular}

Sumber : Ha Data diolah (2018) 
Berdasarkan Tabel 3 di atas menunjukkan bahwa dalam model regresi ini tidak terjadi multikolinearitas. Dibuktikan dari nilai kolerasi tersebut diatas lebih kecil dari 0,80 yaitu sebesar 0.625921588025337 .

\subsubsection{Uji Autokolerasi}

Trabel 4

Hasil Uji Autokolerasi Metode Durbin Watson

Dependent Variable: PE

Method: ARMAMaximumLikelihood(OPG - BHHH)

Date: 08/29/18 Time: $12: 33$

Sample: 2007M01 2016M12

Included observations: 120

Convergence a chieved after 25 iterations

Coefficient covariance computed using outer product of gra dients

\begin{tabular}{lrlrr}
\hline \hline \multicolumn{1}{c}{ Variable } & Coefficient & Std. Error & t-Statistic & Prob. \\
\hline \hline C & 351.3841 & 55.28552 & 6.355807 & 0.0000 \\
PENGANGGURAN & -0.887338 & 0.164301 & -5.400682 & 0.0000 \\
LOG(PENG_PEMERI & & & & \\
NTAH) & -12.06171 & 1.917488 & -6.290368 & 0.0000 \\
AR(1) & 0.924341 & 0.090625 & 10.19968 & 0.0000 \\
$\quad$ SIGMASQ & 6.198020 & 0.535948 & 11.56460 & 0.0000 \\
\hline \hline & & & & \\
R-squared & 0.851469 & Mean dependent var & -0.719750 \\
Adjusted R-squared & 0.846303 & S.D. dependent var & 6.486865 \\
S.E. ofregression & 2.543128 & Akaike info criterion & 4.761498 \\
Sum squared resid & 743.7624 & Schwarz criterion & 4.877644 \\
Loglikelihood & -280.6899 & Hannan-Quinn criter. & 4.808665 \\
F-statistic & 164.8121 & Durbin-Watson stat & 1.913155 \\
Prob(F-statistic) & 0.000000 & & & \\
Sumber : Data diolah (2018) & & & \\
& & &
\end{tabular}

hasil estimasi sebesar 1.913155 dan untuk melihat pengambilan keputusan ada tidaknya autokolerasi dapat dilihat pada tabel berikut :

\section{Tabel 5}

Pengambilan Keputusan Ada Tidaknya Autokolerasi

\begin{tabular}{|c|c|}
\hline D-W & Kesimpulan \\
\hline $\begin{array}{c}\text { Bila nilai D-W } \\
\text { terletak dibawah -2 } \\
\text { dibawah -2 }\end{array}$ & $\begin{array}{c}\text { Ada Autokolerasi } \\
\text { positif }\end{array}$ \\
\hline $\begin{array}{c}\text { Bila nilai D-W } \\
\text { terletak Diantara -2 } \\
\text { sampai }+2\end{array}$ & Tidak ada Autokolerasi \\
\hline $\begin{array}{c}\text { Bila nilai D-W } \\
\text { terletak di atas } \\
+2\end{array}$ & Ada Autokolerasi \\
negatif
\end{tabular}

Sumber : Santoso, 2012

Berdasarkan Tabel 4 dan 5, kesimpulan yang dapat ditarik adalah berdasarkan tabel pengambilan keputusan ada tidaknya autokolerasi adalah tidak ada autokolerasi. Dapat dilihat pada nilai Durbin Watson ( DW ) statistik yang didapat dari hasil regres dengan bantuan Eviews 9 adalah sebesar 1.913155 yang berada di antara -2 sampai +2 .

\subsection{Uji Statistik \\ 4.3.1 Uji Parsial ( Uji-t )}

\author{
Tabel 6
Hasil Uji Parsial ( Uji-t )
}

\begin{tabular}{ccccc}
\hline \hline Variable & Coefficient & Std. Error & t-Statistic & Prob. \\
\hline \hline C & 351.3841 & 55.28552 & 6.355807 & 0.0000 \\
PENGANGGURAN & -0.887338 & 0.164301 & -5.400682 & 0.0000 \\
LOG(PENG_PEMERI & & & & \\
NTAH) & -12.06171 & 1.917488 & -6.290368 & 0.0000
\end{tabular}

Sumber : Hasil Penelitian (2018)

Berdasarkan hasil pengujian yang di tunjukkan dilihat pada tabel 6 diatas dapat dilihat bahwa:

Variabel tingkat pengangguran memiliki nilai $\mathrm{T}$ hitung sebesar -5.400682 dan nilai probabilitas statistiknya sebesar 0.0000 , dan nilai $\mathrm{T}_{\text {tabel }}$ dengan $(\mathrm{df})=\mathrm{n}-\mathrm{k}(10-3)=7$ pada $\mathrm{a}=0.01$ dengan $\mathrm{ta} / 2=0.01 / 2=\mathrm{t} 0.005(10)$ diperoleh nilai sebesar 3.49948 . Dapat disimpulkan bahwa $\mathrm{T}_{\text {hitung }}$ $>\mathrm{T}_{\text {tabel }}$, yaitu $-5.400682>3.49948$ dengan nilai probabilitas $0.0000<0.01$.Maka dapat disimpulkan bahwa secara parsial variabel tingkat pengangguran berpengaruh secara negatif dan signifikan terhadap pertumbuhan ekonomi di Kabupaten Aceh Utara tahun 2007-2016 .

Variabel pengeluaran pemerintah memiliki nilai $\mathrm{T}$ hitung sebesar -6.290368 dan nilai probabilitas statistiknya sebesar 0.0000 , dan nilai $\mathrm{T}_{\text {tabel }}$ dengan $(\mathrm{df})=\mathrm{n}-\mathrm{k}(10-3)=7$ pada $\mathrm{a}=0.01$ dengan $\mathrm{ta} / 2=0.01 / 2=\mathrm{t} 0.005$ ( 10$)$ diperoleh nilai sebesar 3.49948 . Dapat disimpulkan bahwa $\mathrm{T}_{\text {hitung }}$ $>\mathrm{T}_{\text {tabel }}$, yaitu-6.290368>3.49948 dengan nilai probabilitas $0.0000<0.01$.Maka dapat disimpulkan bahwa secara parsial variabel tingkat pengangguran berpengaruh secara negatif dan signifikan terhadap pertumbuhan ekonomi di Kabupaten Aceh Utara tahun 2007-2016. 


\subsubsection{Uji Simultan ( Uji-F )}

Tabel 7

Hasil Uji Simultan ( Uji-F )

\begin{tabular}{lrlr}
\hline \hline R-squared & 0.851469 & Mean dependent var & -0.719750 \\
Adjusted R-squared & 0.846303 & S.D. dependent var & 6.486865 \\
S.E. of regression & 2.543128 & Akaike info criterion & 4.761498 \\
Sum squaredresid & 743.7624 & Schwarz criterion & 4.877644 \\
Loglikelihood & -280.6899 & Hannan-Quinn criter. & 4.808665 \\
F-statistic & 164.8121 & Durbin-Watson stat & 1.913155 \\
Prob(F-statistic) & 0.000000 & \\
Sumber : Hasil Penelitian (2018)
\end{tabular}

Berdasarkan hasil pengujian yang dilakukan secara bersama-sama dari tabel 7 di atas dapat dilihat bahwa nilai $F_{\text {hitung }}$ sebesar 164.8121 dengan nilai probabilitas statistiknya sebesar 0.000000 , sedangkan $F_{\text {tabel }}$ dengan $(\mathrm{df})=\mathrm{n}-\mathrm{k}($ $10-3=7)$ dan $k-1(3-1=2)$ pada $a=0.01$ diperoleh nilai sebesar 9.55 , maka $F_{\text {hitung }}>F_{\text {tabel }}$ yaitu $164.8121>9.55$. Maka dapat disimpulkan bahwa secara simultan ( bersama-sama ) variabel tingkat pengangguran dan pengeluaran pemerintah berpengaruh secara positif dan signifikan terhadap pertumbuhan ekonomi di Kabupaten Aceh Utara tahun 2007-2016.

\subsection{Koefisien Determinasi}

Untuk mengetahui pengaruh tingkat pengangguran dan pengeluaran pemerintah terhadap pertumbuhan ekonomi di Kabupaten Aceh Utara tahun 2007-2016 dapat dilihat dari nilai $R^{2}$. Dari hasil pengujian diperoleh nilai $R^{2}$ sebesar 0.846303 menunjukkan variasi kemampuan variabel tingkat pengangguran dan pengeluaran pemerintah menjelaskan pengaruhnya terhadap pertumbuhan ekonomi di Kabupaten Aceh Utara tahun 2007-2016 sebesar 0.846303 ( $84.6 \%$ ) sementara sisanya yaitu 0.154 ( $15.4 \%$ ) dipengaruhi oleh variabel lain yang tidak di masukkan dalam penelitian ini .

\subsection{Pembahasan}

\subsubsection{Pengaruh Tingkat Pengangguran Terhadap Pertumbuhan Ekonomi}

Berdasarkan pengujian yang telah dilakukan peneliti menyimpulkan bahwa variabel tingkat pengangguran berpengaruh negatif dan signifikan terhadap pertumbuhan ekonomi di Kabupaten Aceh Utara tahun 2007-2016 .

Hasil penelitian penulis sama dengan hasil penelitian sebelumnya yang dilakukan oleh (Pramesthi, 2011), yang menunjukkan bahwa secara parsial variabel pengangguran berpengaruh negatif terhadap pertumbuhan ekonomi di Kabupaten Trenggalek.

\subsubsection{Pengaruh Pengeluaran Pemerintah Terhadap Pertumbuhan Ekonomi}

Berdasarkan pengujian yang telah dilakukan peneliti maka adapun pengaruh pengeluaran pemerintah terhadap pertumbuhan ekonomi di Kabupaten Aceh Utara tahun 20072016 adalah berpengaruh signifikan secara negatif.

Pengeluaran pemerintah berpengaruh secara negatif terhadap pertumbuhan ekonomi di Kabupaten Aceh Utara disebabkan oleh akumulasi pengeluaran pemerintah ternyata lebih besar digunakan untuk belanja rutin, oleh karena itu jumlah belanja pembangunan tidak mampu meningkatkan perekonomian di Kabupaten Aceh Utara.

Hasil penelitian penulis sama dengan hasil penelitian sebelumnya yang dilakukan oleh (Soleh \& Anitasari, 2012). yang menunjukkan bahwa secara parsial variabel pengeluaran pemerintah berpengaruh negatif dan signifikan terhadap pertumbuhan ekonomi di Provinsi Bengkulu.

Pengeluaran pemerintah berpengaruh secara negatif terhadap pertumbuhan ekonomi di Kabupaten Aceh Utara karena disebabkan oleh akumulasi pengeluaran pemerintah ternyata lebih besar digunakan untuk belanja rutin.Oleh karena itu, jumlah belanja pembangunan tidak mampu meningkatkan perekonomian di Kabupaten Aceh Utara.

\section{PENUTUP}

\section{Kesimpulan}

Berdasarkan hasil penelitian pengaruh pengangguran dan pengeluaran pemerintah terhadap pertumbuhan ekonomi di Kabupaten Aceh Utara tahun 2007-2016 yang telah dibahas serta di analisis dengan perhitungan-perhitungan statistik untuk menguji hipotesis yang telah dilakukan dengan analisis regresi linier berganda dan pembahasan analisis yang telah di jelaskan, maka penulis menarik kesimpulan sebagai berikut:

1. Variabel-variabel independent( bebas ) yaitu tingkat pengangguran dan pengeluaran pemerintah secara bersama- 
sama ( simultan ) mempunyai pengaruh secara positif dan signifikan terhadap variabel dependent ( tetap ) pertumbuhan ekonomi di Kabupaten Aceh Utara tahun 2007-2016 . Adapun secara parsial tingkat pengangguran berpengaruh negatif dan signifikan terhadap pertumbuhan ekonomi , sedangkan pengeluaran pemerintah juga berpengaruh negatif dan signifikan terhadap pertumbuhan ekonomi .

2. Besar pengaruh dari variabel tingkat pengangguran dan pengeluaran pemerintah terhadap pertumbuhan ekonomi di Kabupaten Aceh Utara sebesar 0.846303 ( $84.6 \%$ ) sementara sisanya yaitu 0.154 ( $15.4 \%$ ) dipengaruhi oleh variabel lain yang tidak di masukkan dalam penelitian ini .

\subsection{Saran}

Setelah peneliti menganalisis pengaruh tingkat pengangguran dan pengeluaran pemerintah terhadap pertumbuhan ekonomi di Kabupaten Aceh Utara tahun 2007-2016 , maka penulis menyarankan beberapa hal sebagai berikut :

1. Pemerintah harus menciptakan lapangan pekerjaan baru agar terserap tenaga kerja dan pengangguran menurun.

2. Hendaknya pemerintah kabupaten aceh utara lebih baik dalam mengalokasikan anggaran pengeluaran rutin maupun pengeluaran pembangunan secara terarah dan terkendali agar adanya efisiensi dalam pemerintahan dan dapat meningkatkan pertumbuhan ekonomi dan terciptanya kesejahteraan.

3. Pemerintah harus mendorong pengusaha atau masyarakat yang sekarang berkerja di sektor pertanian untuk meningkatkan produksinya agar terciptanya pertumbuhan ekonomi.

\section{KEPUSTAKAAN}

Dumairy. (2006). Perekonomian Indonesia. Jakarta: Erlangga.

Ghozali, I. (2005). Aplikasi ana-lisis multivariate dengan program spss. semarang: Universitas di ponegoro.

Ghozali, I. (2006). Aplikasi analisis multivariate dengan program ibm spss. semarang: UNDIP.

Ghozali, I. (2012). Aplikasi analisis multivariate dengan program ibm spss 20. semarang: UNDIP.

Gujarati, D. (2003). ekonometrika dasar. jakarta: penerbit erlangga.

https://www.google.co.id/search?q=kondisi+perek onomian+masyarakat+aceh+utara\&oq=kond isi+perekonomian+masyarakat+aceh+utara \&aqs $=$ chrome..69i57.14764j1j7\&sourceid $=c$ $\underline{\text { hrome } \& i e=U T F-8}$

Mangkoesoebroto, G. (2002). Ekonomi publik. yogyakarta: BPFE.

Mankiw, N. G. (2007). Makro Ekonomi Edisi Keenam. Jakarta: Erlangga.

Pramesthi, R. N. (2011). Pengaruh Pengangguran Dan Inflasi Terhadap Pertumbuhan Ekonomi Di Sumatera Utara. Jurnal Ekonomi Studi Pembangunan, Vol.1(No.1), 1-20.

Saebeni, A. (2008). Metedelogi Penelitian. Bandung.

Soleh, A., \& Anitasari, M. (2012). Pengaruh Pengeluaran Pemerintah Terhadap Pertumbuhan Ekonomi di Provinsi Bengkulu, 117-127.

Sugiyono. (2010). Metode Penelitian Kuantitatif Kualitatif \& rnd. bandung: alfabeta.

Suindyah, S. (2011). Pengaruh Investasi, tenaga Kerja dan Pengeluaran Pemerintah Terhadap Pertumbuhan Ekonomi di Propinsi Jawa Timur. Jurnal Ekonomi, 15(4), 477-500.

Sukirno, S. (2002). Makro Ekonomi. jakarta: raja grafindo persada.

Kebijaksanaan. jakarta: lpfeui.

Sukirno, S. (2006). Teori Pengantar Makroekonomi .jakarta: pt raja grafindo persada. 